\title{
Handgrip strength and functional class as prognostic factors in elderly patients with heart failure in Colombia. FORCE II study
}

\author{
Amaury Alexis Amarís-Vergara ${ }^{1}$, Gustavo Alejandro Palomino Ariza ${ }^{2 *}$, Betsy Viviana Rodríguez-Hernández ${ }^{3}$, Carlos Alberto Velandia- \\ Carrillo $^{4}$, Miguel Oswaldo Cadena-Sanabria ${ }^{5}$ and Miguel Enrique Ochoa ${ }^{6}$ \\ ${ }^{1}$ Internist, Universidad Autónoma de Bucaramanga (UNAB), Colombia \\ ${ }^{2}$ Internist, Cardiologist, Hospital Militar Central, Profesor, Internal Medicine Department, Universidad Militar Nueva Granada, Bogotá, Colombia \\ ${ }^{3}$ General Physician, Universidad Autónoma de Bucaramanga (UNAB), Colombia \\ ${ }^{4}$ Internist UNAB, Cardiology Resident, Pontificia Universidad Javeriana, Colombia \\ ${ }^{5}$ Internist, Geriatrist, Professor Internal Meidicine Department, UNAB, Universidad Industrial de Santander (UIS), Clínica FOSCAL, Bucaramanga, Colombia \\ ${ }^{6}$ Medical Doctor, MSc in Epidemiology, Clinical Research Group, UNAB, Colombia
}

\begin{abstract}
Introduction: Handgrip strength (HGS) is a measure of skeletal muscle function. There is a correlation between the progression of heart failure (HF) and handgrip reduction.

Objective: to stablish the association between HGS, mortality and hospitalization rates at 18 months follow up in patients with HF.

Methods: a prospective, cohort study, was performed in HF patients belonging to the 2015 FORCE study. They were followed up for 18 months to determine the rate of hospitalization and death in relation to their basal HGS, NYHA functional class and ejection fraction.

Results: 95 out of 120 patients enrolled in the 2015 FORCE study were included. Seventeen patients had died, finding a mortality rate of $17.8 \%$. The remaining 78 patients were followed up for 18 months. The frequency of hospitalization was $78 \%$. In the bivariate analysis higher mortality risk was found in patients with low HGS, RR 2.9 IC 95\% (1.11-7.59). This behavior was also observed in patients with NYHA functional class III and IV, in whom, lower HGS was associated with higher risk of mortality, RR 2.42 IC $95 \%(1.07-5.45)$.

In the multivariate model a significant association was found between the global functional class and mortality, with HR 2.63 IC 95\% (1.4-4.94), being more significant in men. Regarding hospitalization, the mean HGS was lower in hospitalized women vs those who did not present the outcome (18 kg/f vs $22 \mathrm{~kg} / \mathrm{f} \mathrm{p} 0.0261)$

Conclusions: HGS in patients with HF has a significant correlation with NYHA functional class, mortality and hospitalization rates. Its measurement could be a useful tool to increase the detection of patients with advanced HF.
\end{abstract}

\section{Introduction}

It is well known that patients with HF with reduced left ventricular ejection fraction (LVEF) have lower survival rates. LVEF under 20 per cent is usually associated with poor survival rates [1]. Few risk scales have tried predicting mortality risk, among them are: the Seattle Score (SHFM) [2], the Heart Failure Survival Score (HFSS) [3], and more recently the model HF-ACTION that includes as main prognostic variables exercise duration in the cardiopulmonary exercise testing, blood urea nitrogen levels, body mass index and female sex [4].

Handgrip strength (HGS) has been known to be a good indicator of muscle strength in general and predictor of mortality in adults, older adults and patients with other diseases [5,6]. In patients with coronary heart disease, handgrip is usually reduced with age. It is lower in women, and it provides valuable information as a predictor of function of elderly patients with heart disease [7].

Previous reports of studies performed in Japanese patients with HF have shown HGS is associated with mortality even after long term follow up. Handgrip measurement with cut-off values of $32,3 \mathrm{~kg}$, seems to be a simple, practical tool to predict mortality in patients with HF, and it could be even better than variables such as LVEF and pKVO2 [8].

The FORCE study was an analytical, cross sectional study that included 120 patients with HF belonging to the outpatient clinic of the Fundación Oftalmológica de Santander (FOSCAL) in 2015. Clinical and epidemiological characteristics of patients with chronic HF were described, as well as HGS and its association with the New York's Heart Association (NYHA) Functional class [9]. Ischemic cardiomyopathy

${ }^{\star}$ Correspondence to: Gustavo Alejandro Palomino Ariza, Internist, Cardiologist, Hospital Militar Central, Profesor, Internal Medicine Department, Universidad Militar Nueva Granada, Bogotá, Colombia, E-mail: gustavopalominoariza@ hotmail.com

Key words: elderly, heart failure, handgrip strength, dynamometer, sarcopenia, mortality, hospitalization

Received: May 09, 2018; Accepted: May 29, 2018; Published: June 02, 2018 
and Chagas disease were among the most prevalent causes of heart failure, different from what was previously reported worldwide and in South America. Chagas disease was the second most frequent cause of heart disease accounting for $16 \%$ of the cases. It was also found that patients with HF had gradual reduction in HGS in the different NYHA stages, mainly in men [9]. Thus, considering the major role of the HSG in the estimation of survival rates, the objective of this study was to stablish if the HGS was associated with mortality and hospitalization rates at 18 months follow up in patients with HF.

\section{Methods}

A prospective cohort analytical study was performed in FOSCAL clinic in Bucaramanga, Santander, Colombia between 2015 and 2017. The primary outcome was to evaluate mortality for any cause and the secondary outcome the frequency of hospitalizations at 18 months follow up. Inclusion criteria included patients over 18 years of age with diagnosis of HF belonging to the HF outpatient clinic, with echocardiogram showing LVEF $<50 \%$, who had a complete clinical history from the initial evaluation from the FORCE study in 2015. HGS was determined using a JAMAR dynamometer, three measurements were taken in the dominant hand, registering the best value in $\mathrm{kg} / \mathrm{f}$. Anthropometric and sociodemographic characteristics were documented including age, body mass index (BMI), HF etiology, stage of the disease, past medial history of importance and medications taken.

Data analysis: data collected was introduced in an Excel 2010 database and statistical analysis was performed using STATA 13 (Stata corporation ${ }^{\circ}$ ). P value under 0,05 was considered statistically significant. For the descriptive analysis measures of central tendency were used, while for continuous variables measures of dispersion were used (standard deviation). Categorical variables were described using absolute and relative frequencies. Categorized analysis was performed by HGS and low strength, stratifying by HGS through retest and chi square for continuous variables. For categorical variables a KaplanMeier survival analysis was performed, being mortality at 18 months the dependent variable. Clinical and sociodemographic characteristics were evaluated using cox regression. This research was approved by the Institutional ethics committee. Written informed consent was obtained at the beginning of the study.

\section{Results}

Out of 120 patients included in the FORCE study, 25 lost follows up, 9 didn't want to participate in the study and 16 were impossible to reach. A total of 95 patients were included in the study and evaluated at 18 months follow up (Figure 1).

The mean age was $66,36 \pm 11,9$ years (Table 1 ). Most of the patients were mestizo and half of them were retired. $37 \%$ were single at the moment of the study, $45 \%$ were married, $17 \%$ cohabitated. Nine out of ten patients lived in the city. 53,8\% hadn't finished primary school. More than half of the patients had hypertension, $40 \%$ diabetes and dyslipidemia. Three out 10 patients had atrial fibrillation. In $40 \%$ of the patients HF developed as a consequence of ischemic heart disease, followed by Chagas heart disease in $14 \%$ of the patients and hypertension in $10 \%$. The maximum average HGS in the dominant hand was $25,62 \mathrm{~kg} / \mathrm{f} \pm 11,68$, while in the non-dominant hand was 23,6 $\mathrm{kg} / \mathrm{f} \pm 11,01$.

When observing HGS behavior over time, it was noticed that after 18 months it had a gradual reduction in women $(P 0,03)$, different from men where it wasn't statistically significant. In women, HGS reduction

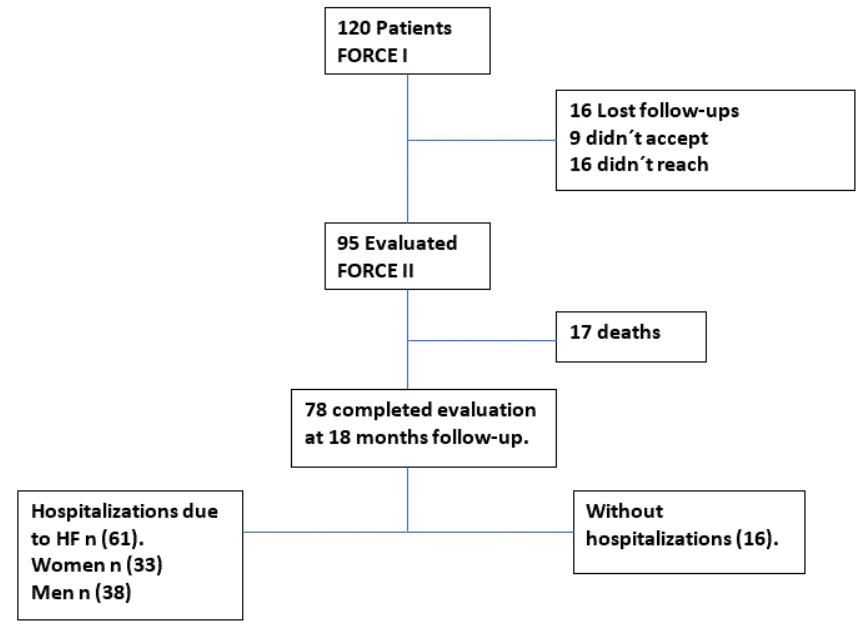

Figure 1: Patient flow chart

Table 1: Sociodemographic variables

\begin{tabular}{|c|c|c|c|c|}
\hline \multirow[t]{2}{*}{ Variables } & $\begin{array}{l}\text { Reduced } \\
\text { strength }\end{array}$ & $\begin{array}{l}\text { Normal } \\
\text { strenght }\end{array}$ & Total & \multirow[t]{2}{*}{$\boldsymbol{P}$} \\
\hline & n (\%) & n (\%) & n (\%) & \\
\hline Aye in years* & 67.8 SD (12.1) & $64.1(11.3)$ & $66.4(11.9)$ & 0.1466 \\
\hline Female gender & $43.1(25)$ & $21.6(8)$ & $34.7(33)$ & 0.032 \\
\hline City living & $94.7(54)$ & $94.6(35)$ & $94.7(89)$ & 0.976 \\
\hline Weight $\mathrm{Kg}^{*}$ & 66.9 SD (15.23) & $72.9(11.3)$ & $69.3(14.07)$ & 0.0431 \\
\hline BMI $\mathrm{Kg} / \mathrm{m}^{2 *}$ & $27.1 \mathrm{SD}(7.7)$ & $26.8(3.5)$ & $26.9(6.4)$ & 0.8353 \\
\hline Calf circumference* & $33.4 \mathrm{SD}(3.6)$ & $34.6(3.1)$ & $33.9(3.5)$ & 0.011 \\
\hline \multicolumn{5}{|c|}{ Marital status } \\
\hline Married & $42.1(24)$ & $51.4(19)$ & $45.7(43)$ & \multirow{5}{*}{0.646} \\
\hline Single & $8.8(5)$ & $10.8(4)$ & $9.6(9)$ & \\
\hline Divorced & $15.8(9)$ & $10.8(4)$ & $13.8(13)$ & \\
\hline Widow & $17.5(10)$ & $8.1(3)$ & $13.8(13)$ & \\
\hline Cohabitating & $15.8(9)$ & $18.9(7)$ & $17.0(16)$ & \\
\hline \multicolumn{5}{|c|}{ Schooling } \\
\hline None & $1.8(1)$ & $2.8(1)$ & $2.2(2)$ & \multirow{6}{*}{0.421} \\
\hline$<5$ Primary school & $54.4(31)$ & $47.2(17)$ & $51.6(48)$ & \\
\hline $6-9$ & $12.3(7)$ & $8.3(3)$ & $10.8(10)$ & \\
\hline $10-11$ & $17.5(10)$ & $13.9(5)$ & $16.1(15)$ & \\
\hline Tecnichal career & $5.3(3)$ & $19.4(7)$ & $10.8(10)$ & \\
\hline Universitary & $8.8(5)$ & $8.3(3)$ & $8.6(8)$ & \\
\hline
\end{tabular}

"Average(SD)

was observed in $62 \%$ of the patients, and it was increased in $23 \%$. In men HGS reduction was observed in one third of the patients, while it was increased in half of them (P 0,023). (Figure 2).

It was found that $78 \%$ of the patients were hospitalized in the follow up period. $38 \%$ were women, in whom reduced HGS was associated with higher admission rates $(P 0,026) .62 \%$ of admitted patients were men, finding a similar behavior in HGS, where patients with lower HGS had higher rates of admission.

\section{Mortality and handgrip strength}

The mortality rate was $17.8 \%$. Reduced HGS was associated with lower survival probability at 18 months follow up. In the analysis of mortality according to HGS for the $20^{\text {th }}$ percentile ( $28 \mathrm{Kg}$ in men and 18 $\mathrm{Kg}$ in women) the RR was $2.78 \mathrm{CI} 95 \%(1.22-6.37)(P 0,015)$.

The mean HGS for men was $32 \mathrm{Kg}$ and $20 \mathrm{Kg}$ in women, RR 0.46 CI95\% (0.18-1.21) (P 0.12). 


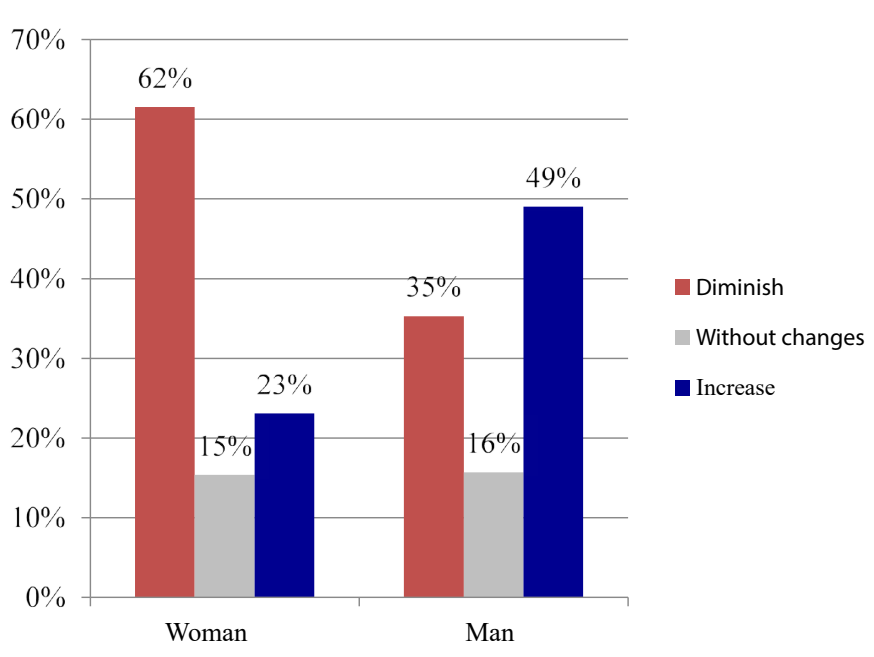

Figure 2: Handgrip change according to gender

Regarding HGS, age, functional class, diabetes, male sex, smoke, a significant increase in the risk of mortality was found only for the functional class in the multivariate analysis, HR 2.63 CI 95\% (1.4-4.94). Additionally, there were no differences found between alive and dead patients regarding clinical variables such as age, BMI, LVEF and calf circumference. A similar tendency was seen when taking into account the etiology of HF and variables such as smoke and diabetes. The discriminatory capacity of the HGS for predicting mortality in women and men was moderate, with areas under the curve of 0.656 and 0.676 respectively.

\section{Discussion}

Previous studies have reported similar mortality rates to the ones found in the present cohort. Dokainish $\mathrm{H}$ et al. reported a mortality rate of $16.5 \%$ with an important geographical variation, highlighting $9 \%$ mortality rate in South America [10]. In our study, the mortality rate was $16.8 \%$ finding similar prognostic factors, such as NYHA functional class and BMI. Patients with chronic HF show atrophy and weakness of the larger muscle groups needed for locomotion, increasing fatigue, which correlates with HF severity [11]. Loss of skeletal muscle mass and its functions associated to aging is known as sarcopenia, being present in up to $20 \%$ of patients with HF [12]. The accentuated inflammatory process that leads to protein consumption and muscle wasting in terminal heart disease is known as cardiac cachexia [13]. Both entities present decreased values of muscle performance. However, they have specific diagnostic criteria that were not differentiated in this study. Sarcopenia's prognostic importance has been well stablished in patients with HF [14]. A BMI under $21.5 \mathrm{~kg} / \mathrm{m}^{2}$ is associated with cachexia and remains as an independent and significant factor for predicting survival [11]. In our study, the mean BMI was $27.1 \mathrm{~kg} / \mathrm{m}^{2}$ in patients with decreased strength, but this data wasn't statistically significant. HGS is highly related to elbow flexion strength, knee extension and trunk extension $[15,16]$. Using them for the patient's approach could avoid some of the big problems for testing large muscle groups in patients with advanced HF with minimum tolerance to physical activity [17]. HGS has shown to be an independent predictor of adverse results regarding health and mortality in different populations $[8,18,19]$. It was found in the present study that the lower the HGS the greater the risk of mortality in patients with HF and decline in functional class for stages
III and IV with statistically significant values. These data are similar to what was previously reported in other population of patients where HGS reduction provided valuable information allowing the prediction of the integrity of the physical condition in elderly patients with HF [11].

Additionally, it should be highlighted that recent evidence shows that training programs could increase the quality of life of patients with HF NYHA class II or III with LVEF $>40 \%$, as well as reducing hospitalization rates for HF. The current evidence does not show increase risk of death in patients who perform physical activity [20]. Aerobic and resistance exercises performed under supervision, such as cardiac rehabilitation programs are key in the intervention of this group of patients, especially those patients with lower muscle strength and sarcopenia [21].

\section{Conclusions}

In elderly patients with HF there is a correlation between NYHA functional class and HGS with mortality and hospitalization rates. The current study supports the evidence that justify further prospective studies with higher number of patients and time of follow up to reassure this association and that also evaluate the impact of intervening muscular function in the progression of HF.

\section{Declarations}

Funding sources: no funding was required for the development of the present study.

Conflict of interest: The authors declare none of them have conflicts of interest.

\section{References}

1. Gradman A, Deedwania P, Cody R, Massie B, Packer M, et al. (1989) Predictors of total mortality and sudden death in mild to moderate heart failure. $\mathrm{J} \mathrm{Am} \mathrm{Coll} \mathrm{Cardiol}$ 14: 564-750. [Crossref]

2. Levy WC, Mozaffarian D, Linker DT, Sutradhar SC, Anker SD, et al. (2006) The Seattle Heart Failure Model: Prediction of survival in heart failure. Circulation 113: 1424-1433. [Crossref]

3. Aaronson KD, Schwartz JS, Chen TM, Wong KL, Goin JE, et al. (1997) Development and Prospective Validation of a Clinical Index to Predict Survival in Ambulatory Patients Referred for Cardiac Transplant Evaluation. Circulation 95: 2660. [Crossref]

4. O'Connor CM, Whellan DJ, Lee KL, Keteyian SJ, Cooper LS, et al. (2009) Efficacy and safety of exercise training in patients with chronic heart failure: HF-ACTION randomized controlled trial. JAMA 301: 1439-1450. [Crossref]

5. Sasaki H, Kasagi F, Yamada M, Fujita S (2007) Grip strength predicts cause-specific mortality in middle-aged and elderly persons. Am J Med 120: 337-342. [Crossref]

6. Jeune B, Skytthe A, Cournil A, Greco V, Gampe J, et al. (2006) Handgrip strength among nonagenarians and centenarians in three European regions. J Gerontol A Biol Sci Med Sci 61: 707-712. [Crossref]

7. Mroszczyk-McDonald A, Savage P, Ades P (2007) Handgrip Strength in Cardiac Rehabilitation. J Cardiopulm Rehabil Prev 27: 298-302. [Crossref]

8. Izawa KP, Watanabe S, Osada N, Kasahara Y, Yokoyama H, et al. (2009) Handgrip strength as a predictor of prognosis in Japanese patients with congestive heart failure. Eur J Cardiovasc Prev Rehabil 16: 21-27. [Crossref]

9. Cadena M, Velandia C (2017) Relationship between handgrip strength and functional class in elderly patients with heart failure. Innov Aging 1: 245-246.

10. Dokainish H, Teo K, Zhu J, Roy A, AlHabib KF, et al. (2017) Global mortality variations in patients with heart failure: results from the International Congestive Heart Failure (INTER-CHF) prospective cohort study. Lancet Glob Health 5: e665-e672. [Crossref]

11. The SOLVD Investigators (1992) Effect of enalapril on mortality and the development of heart failure in asymptomatic patients with reduced left ventricular ejection fractions Massachusetts Medical Society. All rights reserved. N Engl J Med. 
12. Fulster S, Tacke M, Sandek A, Ebner N, Tschope C, et al. (2013) Muscle wasting in patients with chronic heart failure: results from the studies investigating co-morbidities aggravating heart fail- ure (SICA-HF). Eur Heart J 34: 512-519. [Crossref]

13. Springer J, Springer JI, Anker SD (2017) Muscle wasting and sarcopenia in heart failure and beyond: update 2017. ESC Heart Fail 4: 492-498. [Crossref]

14. Vescovo G, Volterrani M, Zennaro R, Sandri M, Ceconi C, et al. (2000) Apoptosis in the skeletal muscle of patients with heart failure: Investigation of clinical and biochemical changes. Heart 84: 431-437. [Crossref]

15. Massy-Westropp NM, Gill TK, Taylor AW, Bohannon RW, Hill CL (2011) Hand Grip Strength: age and gender stratified normative data in a population-based study. $B M C$ Res Notes 4: 127.

16. Trampisch US, Franke J, Jedamzik N, Hinrichs T, Platen P (2012) Optimal jamar dynamometer handle position to assess maximal isometric hand grip strength in epidemiological studies. J Hand Surg Am 37: 2368-2373. [Crossref]
17. Rantanen T, Volpato S, Luigi Ferrucci M, Eino Heikkinen M, Fried LP, et al (2003) Handgrip Strength and Cause-Specific and Total Mortality in Older Disabled Women: Exploring the Mechanism. J Am Geriatr Soc 51: 636-641. [Crossref]

18. Bohannon RW (2008) Hand-grip dynamometry predicts future outcomes in aging adults. J Geriatr Phys Ther 31: 3-10. [Crossref]

19. Chang YT, Wu HL, Guo HR, Cheng YY, Tseng CC, et al. (2011) Handgrip strength is an independent predictor of renal outcomes in patients with chronic kidney diseases. Nephrol Dial Transplant 26: 3588-3595. [Crossref]

20. Taylor RS, Sagar VA, Davies EJ, Briscoe S, Coats AJ (2014) Exercise-based rehabilitation for heart failure. Cochrane Database Syst Rev. [Crossref]

21. Onoue Y, Izumiya Y, Hanatani S, Tanaka T, Yamamura S, et al. (2016) A simple sarcopenia screening test predicts future adverse events in patients with heart failure. Int J Cardiol 215: 301-306. [Crossref]

Copyright: (C2018 Amarís-Vergara AA. This is an open-access article distributed under the terms of the Creative Commons Attribution License, which permits unrestricted use, distribution, and reproduction in any medium, provided the original author and source are credited. 